\title{
EFL Teachers' Perceptions of Strategy Deficiency Syndrome: A Grounded Theory Study
}

\author{
Seyyed Ali Ostovar-Namaghi ${ }^{1} \&$ Bahareh Ahmadabadi-Tak ${ }^{1}$ \\ ${ }^{1}$ Shahrood University of Technology, Iran \\ Correspondence: Seyyed Ali Ostovar-Namaghi, Shahrood University of Technology, Iran. E-mail: \\ saostovarnamaghi@yahoo.com
}

Received: June 10, 2017 Accepted: October 18, 2017 Online Published: October 23, 2017

doi: 10.5539/elt.v10n11p204 URL: http://doi.org/10.5539/elt.v10n11p204

\begin{abstract}
Strategy-deficient language learners struggle to develop their language proficiency through limiting and inappropriate strategies. This study aims at exploring experienced teachers' perceptions of strategy deficiency syndrome among EFL learners. To this end, the perspectives of a purposive sample of experienced teachers teaching in private language schools of Tehran, the capital city of Iran, were theoretically sampled based on the principles and procedures of grounded theory. The final conceptualization of teachers' perspectives yielded "learners' limiting strategies" and "teachers proposed alternatives" as the major categories. The findings suggest that curriculum developers and language teachers merge strategy training and language teaching to remedy the strategy deficiency syndrome among EFL learners in the contexts of this study and other similar contexts where the banking model of education marginalizes strategy training and focuses exclusively on language teaching.
\end{abstract}

Keywords: learners, limiting strategies, teachers, alternative strategies, learning strategies

\section{Introduction}

There has been a shift away from language teaching towards strategy training in many contexts. However, in public and private language schools of Iran the transmission model of education not only has marginalized strategy training but also has led to strategy deficiency syndrome among EFL learners. Having been deprived of strategy training, strategy-deficient language learners painstakingly try to develop their language proficiency through inefficient and limiting strategies. Despite the fact that in many contexts, including private language schools of Iran, strategy deficient language learning is the norm, very little has been done to cure this educational ill; hence, the field is in urgent need of data-driven studies which aim at uncovering strategy deficient language learners' limiting strategies and teachers' proposed alternatives. Only then will curriculum developers and policy makers be able to take informed measures to institutionalize strategy efficient language learning as a substitute for strategy-deficient language learning and recognize strategy training as an unalienable part of language teaching. As a rule of thumb, learning to learn precedes learning.

This study is significant since conceptualizing learners' inefficient strategies together with teachers' proposed alternatives: (1) significantly improve the knowledge-base of language learning strategies; (2) result in down-to-earth, responsive, and context-sensitive strategies to be replaced with top-down theory-based strategies wrongly supposed to be applicable across varied contexts; (3) pave the way for a shift away from teaching which is still dominant in public and private language schools of Iran towards strategy training and the resultant learner autonomy; and (4) provide syllabus designers and curriculum developers with empowering suggestions for instilling strategy training as an inseparable part of language teaching materials.

\subsection{Literature Review}

Some scholars have focused on defining learning strategies. Oxford and Cohen (1992, p. 1) defined it as "steps or actions taken by learners to improve the development of their language skills". On the other hand,Wenden and Rubin (1987) defined language learning strategies as " any sets of operations, steps, plans, routines used by the learners to facilitate the obtaining, storage, retrieval and usage of information"(p.19).

Other scholars have tried to specify characteristics of successful language learners. Rubin (1975) identified seven general characteristics of good language learners' strategies, which include being an accurate guesser, learning from communication, willing to make mistake, practice, monitoring his/her/other speeches, and lastly attending 
to meaning rather than form and grammar. Moreover, Stern (1975) provided a list of features that mark out good language learners, the most prominent of which is learning style and strategies.

There are other scholars who have done their best to classify learning strategies. Oxford's (1990) strategy classification system is made up of two main categories of direct and indirect strategies. Direct strategies consist of memory, cognitive and compensation strategies. On the contrary, indirect strategies include metacognitive strategies, affective strategies and social strategies. Cohen (2002) classifies learning strategies into retrieval strategies, rehearsal strategies, cover strategies and communication strategies.

Going beyond defining or classifying learning strategies, other scholars have tried to present the field with empirical findings reflecting the positive effect of learning strategies on learners' language development. Ehrman and Oxford (1990) investigated adults' use of language learning styles and strategies in an intensive training setting. The results of their study indicated that psychological and personality type have a significant effect on the way learners use strategies. Further, Ehrman and Oxford (1989) conducted a study on the impact of learners' psychological type on language learning strategies and found that learners use learning strategies based on their personality type; for instance, extroverts report greater use of affective strategies.

While Catalan (2003) investigated sex differences in L2 vocabulary learning strategies and found that males and females are different in the range of strategies they use, Abbot (2006) explored the role of learners' mother tongue of strategy use and found that the Mandarin ESL learners highly benefited from breaking a word into smaller parts, scanning, paraphrasing, and matching strategies; while, the Arabic ESL learners mostly made use of skimming, connecting, and inferring strategies.With quite a different focus, Diaz and Laguado (2013) and Ulmi, Sundari and Sukmaantara (2015) found that the use of scanning and skimming techniques contributed to reading comprehension of language learners.

Rather than investigating what shape strategy use, others have focused on the effect of strategy training. For instance, Nakatani (2005) found a significant improvement in the oral proficiency of those students instructed through strategy training. Likewise, Dornyei (1995)investigated the effect of teaching communication strategies on the learners' fluency and found that less fluent learners can benefit from using time-gaining strategies to become more fluent in their communication skill.Similarly, Vandergrift (2002) found that the students' listening comprehension was highly improved with the help of strategy-based instruction through which their metacognitive awareness was raised.

In a nutshell, while the positive effects of strategy training has been repeatedly verified in different contexts, in private and public language schools of Iran, language teaches still see their role as teaching rather than strategy training. Consequently, in this context like many other similar contexts, EFL learners painstakingly develop their language proficiency using inappropriate and limiting strategies. Thus in a drastic contrast with the empirical studies reviewed, the field is in urgent need of data-driven studies that aim at uncovering self-made ineffective and limiting strategies used by strategy decicient language learners who have been deprived of the possible benefits of strategy training.

\subsection{Purpose of the Study}

To fill in the previously identified gap, i.e., dearth of knowledge of the inappropriate and limiting strategies used by struggling EFL learners who painstakingly develop their language proficiency within the transmission model of language education which leaves no room for strategy training, this study aims at: (1) uncovering EFL teachers' awareness of limiting and limited strategies used by EFL learners; and (2) theorizing their suggested alternative strategies. More specifically, this study aims at answering the grand tour question, "Without any strategy training, what strategies do your students use and what alternative strategies do you recommend for the limiting strategies they use?"

\section{Methodology}

\subsection{Participants}

To theorize experienced teachers' perceptions of inappropriate strategy use and conceptualize their suggested alternative strategies, this study selected interested participants who were willing to share their views with us were selected on the basis of snowball sampling, purposive sampling and theoretical sampling. The participants were selected from private language schools of Tehran, the capital city of Iran. The study started with interviewing an experienced female teacher who happened to be a close friend. After the interview, she recommended other interested researchers. Rather than selecting a statistically representative sample, we exercised our professional judgment in selecting participants. Moreover, having selected the qualified and interested participants, we tried to sample theoretically relevant information. Sampling participants and concepts 
ended when the emerged limiting strategies and the recommended alternative strategies were clear enough and reached a point of theoretical saturation. All in all, eleven participants, five females and six males shared their perspectives with us.

\subsection{Ethical Considerations}

Prior to interviews, the participants became cognizant with the research purpose and procedure. Moreover, their informed consent was sought and they were assured that their perspectives would not be disclosed to any third parties. To ensure that they can express their perspectives with ease and fluency, interviews were conducted in their mother tongue. Finally, they were assured that the final abstraction and conceptualization of their perspectives would be shown to them for verification and any possible modification.

\subsection{Data Collection and Analysis}

We elicited the participants' perceptions of limiting learner strategies and their suggested alternative strategies in the iterative process of data collection and analysis. Procedurally, in an initial round of data collection and analysis, the first participant's perspectives concerning limiting learner strategies and her proposed alternative strategies, were audio-taped, transcribed verbatim, and repeatedly read through line by line to develop transient concepts and categories. The emerged concepts and categories were then used to collect theoretically-relevant information from the same participant and other participants. The final conceptualization and abstraction of the participants' perspectives were developed through the constant comparative technique. Iterative data collection and analysis continued till further interviews seemed redundant. To establish the credibility of the findings, transient and final concepts and categories were verified and at times modified through what is commonly known as member checking.

\section{Findings}

Having collected and analyzed research data, the researchers came up with two major categories, namely inappropriate learner strategies and teachers' alternative strategies, each of which contains some subcategories. What follows aims at introducing and substantiating the emerged categories and subcategories.

\subsection{Learners' Limiting Strategies}

The first elicited category fell into seven sub-categories, namely (a) learning new words in isolation, (b) overuse of dictionaries,(c) atomistic analysis of texts, (d) watching movies passively, (e) interest-based learning,(f) mood-based learningand $(\mathrm{g})$ memorizing grammar rules.

\subsubsection{Learning New Words in Isolation}

As the participants observed, strategy deficiency language learners (SDLLs) memorize isolated words with their Persian equivalents. To this end, they study large numbers of words repeatedly until they stick in their mind. Participants had a deem view of this strategy.Verifying this point, participant B states:

SDLLs prefer to make a long list of new words with their equivalent translation in Persian. Then, they devote considerable time to memorize the words by constant repetition. When the words are memorized, they consider those words as learned materials and make another list of new words. However, memorized words are inefficient and short-lived.

Another limiting learner strategy recognized by the participants was memorizing synonyms and antonyms. Participants found this inappropriate since they believe they are of little use in reading, writing and other language skills. Moreover, they believe what learners do not recognize is that the use of language forms is far from universal. That is, while they learn the meaning of words through synonyms, they don't learn the context in which the word or its synonym is used. Supporting this issue, participants $\mathrm{C}$ comments:

Language learners are interested in creating vocabulary notebooks, which are replete with isolated words. The words are generally combined with their synonyms, and antonyms that are isolated as well.They try to fill their mind with isolatedwords while they do not know how to make a sentence with the words.

\subsubsection{Overuse of Dictionaries}

According to the participants, SDLLs rely heavily upon using dictionaries to overcome their comprehension barriers. They believe overuse of dictionaries hinders comprehension. In line with the participants' concern, Hartmann (2003) states, "the reason why dictionaries are harmful is that learners use them before attempting an intelligent guess, and consequently never learn how to guess intelligently" (p. 304). Expressing her concern over dictionary use, participants B states:

The problem with SDLLs is that without a dictionary, they think of themselves as unarmed soldiers. When they 
read a text, they constantly use dictionaries to find the meaning of every single word ofthe text.They wrongly believe thatcomprehension does not take place unless they know the meaning of every single word.

SDLLs cannot be selective about what unknown words are important to comprehend a text or useful to learn. Therefore, they try to look up every unknown word they come up with. Participant $\mathrm{G}$ better explains this issue:

Overuse of dictionaries may affect fluency, comprehension and speed of text processing. However, language learners generally cannot put dictionary aside since they are not able to distinguish between redundant words and necessary ones. In a nutshell, dictionary overuse shifts learners'attention away from meaning towards form.

\subsubsection{Atomistic Analysis of Texts}

As the results indicated, SDLLs wrongly suppose that text comprehension is highly dependent on understanding all the words and sentences of the text. However, in some cases it is required to adopt a holistic approach towards texts rather than an atomistic one in order to get the overall message of the texts. On this issue, participant $\mathrm{C}$ asserts:

SDLLs believe that, a text can be comprehended only if all its words are understood. However, in most cases they should have a holistic view toward texts rather than breaking it into separated, unrelated words, since it is sufficient to get the gist of the message.

The results also show that learners' atomistic approach towards texts stems from their low ambiguity tolerance. Supporting this issue, participant $\mathrm{C}$ states:

Learners try to understand every single component of texts they hear or read. However, we do not have full mastery even over our mother tongue. Even in our mother tongue while reading texts e face lots of unknown words. Still, we use our analytic power to get the message. I believe dictionary overuse indicates learners' low ambiguity tolerance.

\subsubsection{WatchingTV Passively}

Another problem diagnosed by the participants is that SDLLs wrongly supposethat lying on the sofa in front of TV and watching the movies passively improves their proficiency. They are not aware of the fact that learning entails active participation. ParticipantA better explains this issue:

SDLLs see no difference between watching to learn and watching for fun. While watching TV for fun is a pastime activity, watching movies to learn entails active participation just like any other academic tasks. To be effective, learners should sit at their desk and make notes to get information and later use those notes to give information in the form of writing or speaking.

\subsubsection{Interest-Based Learning}

As the participants observed, SDLLs generally show great interest in learning specific aspects of language while they are unwilling to learn other aspects. Therefore, there is generally no balance between their acquired skills and the required skills of the target language. As one of participant $F$ asserts:

SDLLs devote most of their time on improving those areas, which they show more interest in.However, knowing a language is not limited to a specific skill or sub skill. In order to be a proficient language user, they have to put an equal amount of time and effort in learning all language skills and sub skills.

Among language learning strategies, vocabulary and reading receive much more attention than other skills.Nonetheless, the components of a language are integrated and cannot be separated from each other; hence, they require equal attention. Showing her concern over learner's focus on some areas at the cost of others, participantE states:

There is a number of advanced SDLLs or even teacher learners, which do not have equal proficiency in all aspects of the target language. They are generally obsessed with specific aspects of language such as vocabulary and reading while marginalizing other aspects, the most prominent example of which is writing.

\subsubsection{Mood-Based Learning}

Foreign language learning is a time-consuming and tricky job, which can hardly be achieved if there is not a consistent, daily schedule. However, SDLLs generally do not follow a regular schedule. They mostly follow an unplanned mood-based learning that is sometimes set aside for a long time. In this regard, participant G explains:

Except for those who learn a language for a specific purpose, you can hardly find a student with a pre-determined daily schedule regarding their practice. Whenever they find themselves in the mood, they open their books and start studying; therefore, while they may study for one whole day at one occasion, they may 
forget about it for two or three consecutive days.

As the participants observed, SDLLs focus on one skill and ignore other skills. As such they get bored. Criticizing learners' approach, participant B states:

SDLLs keep learning a specific skill of language for days while they do not spend a minute for other skills. As a result, they become bored after a while and stop studying. However, language learning should follow an ongoing uniform program, which involves all skills and sub skills. Putting it differently, there must be a parallel, identical progress in all four skills and sub skills; therefore, an equal amount of time should be allocated to all of them.

\subsubsection{Memorizing Grammar Rules}

As the analysis indicates, rote learning is still the most prevalent strategy among language learners, not only to learn vocabularies but also to memorize grammar points. As the participants noted, they learn forms without learning the functions for which it can be used. Learning a grammatical structure is quite different from using it to communicate meaning. Participant $\mathrm{H}$ better illustrates this problem:

SDLLs adopt a form-based strategy for mastering grammar rules; that is, they memorize a specific rule, irrespective of the function for it can serve. They spend a considerable amount of time memorizing the rules by repetition, but when it comes to using them, they feel quite incompetent.

SDLLs' approach has been shaped by the dominant formalist approach. When teaching is form-focused, automatically, learning is form-focused. In many contexts, teachers present rules in the form of mathematical formulas and make students memorize them.Rejecting the formalist approach, Participant $\mathrm{F}$ explains:

SDELLs memorize grammar rules like mathematical formulas. For instance, they memorize past perfect tense formula (subject $+h a d+p p$ ) with constant repetition regardless of its use in different sentences. Consequently, they are familiar with a large number of grammar rules while they do not know how to use them when it comes to production.

\subsection{Teachers' Alternative Strategies}

The participants of the present study mentioned some alternative strategies to help SDLLs.The proposed strategies fall into eight main categories including: (a) ignoring redundant words, (b) guessing the meaning of key words through co-text and morphemic analysis,(c) skimming and scanning; (d) de-isolation of unknown words throughlinking, (e) memorizing formulaic phrases and contextualizing; (f) watching movies actively,(g) disassembling authentic texts and (h) planning.

\subsubsection{Ignoring Unnecessary Words}

Having encountered an unknown word, SDLLsgenerally check a dictionary on impulse irrespective of its necessity. However, before consulting a dictionary, they should determine whether knowing the meaning of the word is necessary for comprehensionor not. This does not mean that learning words should be ignored as a separate objective. Irrespective of how many words one knows, s/he naturally faces new words. These new words should not hinder comprehension. That is, SDLLs should be taught to understand the text without checking the meaning of each and every word in the dictionary. Rejecting dictionary overuse, participant A states:

It is not necessary to know every single word of text and talk. Learners should distinguish those words, which play the key role from decorative ones and ignore the second group. Ignoring is one of those helpful strategies, which improves the reading speed and comprehension. The same is true when it comes to listening. Using dictionaries should be regarded as a last resort, when there is no other way to comprehend the text.

SDLLs believe that comprehension takes place only in case of having complete mastery over language forms. Theoretically this is not possible because no one ever has mastery over all English words and as such there are always new words in the texts and talks we encounter. SDLLsshould learn to tolerate ambiguity, guess the meaning of unknown words, and keep reading by skipping unknown words. As Day and Bamfored note, "part of fluent and effective reading involves the reader ignoring unknown words and phrases" (1998, p. 93). Reiterating this rule of thumb, participant $\mathrm{K}$ states:

Owing to the nature of second/foreign language, language learners always face unknown language forms. Nonetheless, they should understand the flow of information by reading strategically. For instance, they can guess the meaning of the unknown word from context or morphologicalanalysis. Similarly, using their analytic power, they can guess the parts, i.e., unknown words by reading holistically rather than atomistically. 
SDLLs are heavily dependent on dictionaries in case of encountering unknown words, phrases or idioms. As a remedy, teachers have found it effective to guess the meaning of new words based on what comes before and after them. Signal words, illustrations, examples and linguistic clues are samples of contextual clues, which indirectly help readers to guess the meaning of unknown words and phrases (Rizvi, 2005). Emphasizing the role of context in clarifying the meaning of unknown words, participant $\mathrm{G}$ states:

I recommend my students not to be too much dictionary-bound to check every single unknown word. In this regard, I encourage my students to manipulate contextual clues or the reader logic and common sense in order to guess the meaning of unfamiliar words or phrases.

Learning moves from known to unknown; hence, reading comprehension entails using what you know to guess what you don't know. Explaining this fact, participant A states:

I train language learners to go from known to unknown. For example, every text contains a number of words that students are familiar with; learners should use the information gained from known words and what they already know about the topic to guess the meaning of unknown phrases or words.

\subsubsection{Guessing Meaning through Morphological Analysis}

When context does not provide enough clues to guess the meaning of unknown words, morphological analysis is a helpful strategy to determine the meaning of new words. To uncover the meaning of some unknown words, learners can break the word into itsprefix, suffix, and root to guess its meaning. On the importance of morphological analysis, participant $\mathrm{K}$ states:

Sometimes being familiar with prefix or the root word may suffice to get the overall meaning of a word. For example, you encounter the word 'disadvantageous' in a text, which can be broken down into three components, dis+advantage+ous. The prefix dis- and the suffix -ous indicate negativity, and the adjective of the word advantage respectively.

SDLLs' overdependence on dictionaries derails them from the task of getting the flow of information. Participants believed that teaching them the meaning of frequently occurring prefixes, suffixes and root words significantly improves their reading efficiency. Explaining how he teaches the morphological structure of words, participants E states:

Word structure analysis is a good way to guess the meaning of an unknown word. In order to make language learners familiar with this strategy, I explain segments of a word and provide a list of English high-frequency roots, suffixes and prefixes with meaning for them. The generative feature of these segments helps language learners to guess the meaning of a number of words by memorizing the meaning of limited numbers of roots, prefixes and suffixes.

\subsubsection{Skimming and Scanning}

Participants believed that skimming and scanning speed up and facilitate SDLLs'reading skill. In addition, these strategies help them to read for meaning, focus on the meaning carrying elements, and do away with redundant parts of the texts. Elaborating the importance of these strategies, participant Fstates:

I always suggest scanning and skimming as two crucial strategies for a purpose-bound reading, which are suggested when time matters.SDLLs should know that locating a specific piece of information depends on skipping irrelevant parts of the texts rather than attending each and every word. Similarly, finding the main point does not depend on knowing and reading all the words. Rather it is a selective process. I introduce and illustrate these strategies early on to move them away from reading comprehension towards reading strategies.

Scanning and skimming are likened to the way we read magazines or newspapers in our mother tongue. When we read a newspaper, firstly we glance through the titles, headlines or the opening lines to get the gist of the news, and then if we are willing to get more detail about specific news we go through the lines and read it precisely. Reiterating the importance of familiarizing SDLLs with skimming and scanning, participant B says:

Skimming and scanning helps learners answer reading comprehension question without fretting over unknown words. I encourage them to read reading comprehension passages the way they read newspapers or surf the net. Reading the news or surfing the net is far from attending each and every word in the text. Rather, it is a selective and rapid process of locating what we want and getting the gist of it. SDLLs wrongly suppose getting the information depends on knowing each and every word in the text.

\subsubsection{De-isolation of New Words}

The first limiting strategy diagnosed by the participants was SDLLs' memorizing long lists of isolated words. To 
cure this educational ill, they recommended three strategies: grouping words, memorizing formulaic phrases and learning words in context of new words.

\subsubsection{Grouping Words}

A significant aid to learn new words is to study them in groups that share common features. This facilitates ease of storage and retrieval. Participants believed that SDLLs would be much better off if they learned word families instead of single isolated words. Word family knowledge enables language learners to decode large numbers of multisyllabic words and improves 'word recognition' (Rusinski \& Heym, 2008, Broun \& Oelwein, 2007). Explaining the rationale behind learning word families as a remedy, participant I states:

Learning word families instead of isolated words would be useful in learning the words and finding the meaning of other words. For example, learners are familiar with the words ease and disease separately but they do not know both of them are members of a word family. Similarly, words such as dictionary, diction, dictation, dictator, prediction and predictable belong to the same family and as such they should be learned together not one by one. Most learners don't know that these words have the same root.

Learning groups of related words, which are similar in structure, combination of letters or sound, would be much more helpful than learning a bunch of unrelated words. By doing this, recalling and recognition of words would be easier. On this issue, participants $\mathrm{F}$ asserts:

One of the effective ways to substitute for learning words in isolation is to put them in groups of related words, which have some of the same combinations of sounds or letters. This grouping contains groups of word families like age, cage, rage, page and homage. Similarly they can group words based on homonymy, homophony and hyponymy. Such groupings facilitate learning and using words since our brain likes classifications of any sort.

\subsubsection{Memorizing Formulaic Phrases or Expressions}

As the analysis indicates, learning words in the form of formulaic phrases is another efficient alternative strategy for isolated word learning. Formulaic language units are 'multiword sequenced units', which are received through the input as discrete elements but stored as a whole in long-term memory (Wood, 2002). Researchers have proposed different types of these unitsincluding fixed phrases, idioms, clauses, 'sentence-building frameworks of words', proverbs and sayings (Schmitt, 2004, Wood, 2002). Recommending fixed phrases as an alternative for isolated words, participant $\mathrm{F}$ states:

When you remember phrases instead of single words, you ensure that you know how to use the word in at least one sentence. For instance, instead of memorizing the word "bunch" it is better to memorize the phrase "a bunch of grapes". Instead of memorizing the verb "occur", it is better to memorize "if any problems occur". Rather than memorizing the meaning of the word 'line', SDLLs can learn phrases such as convergent lines, divergent lines, parallel lines, diagonal line, curved line and the like.

Native speakers speak and listen fluently since their brain is full of fixed phrases. Rather than putting isolated words together, they put memorized phrases together to encode and decode meaning. Wood (2002) asserted that these fixed chunks of language proved to be an important part of language learning, in particular fluent language production; since, "they allow language production to occur while bypassing controlled processing and the constraints of short-term memory capacity" (p. 1). However, it also eases listening process (Schmit\& Carter, 2000). On this issue, participant $\mathrm{H}$ states:

When language learners read, listen or watch movies they should be sensitive not only to key words, but also to those chunks or lexical phrases they find useful to speak or write. Storing lexical phrases in mind in the form of chunks as a single concept help language learners to build their writing and speaking fluency.

\subsubsection{Learning Words in Context}

Placing or studying words in contexts facilitate learning, retrieving, and using new words for learners. While contextualized vocabulary learning is at the very foundation of vocabulary improvement, decontexulaized vocabulary learning is of limited value. There is a big difference between learning words and using words. When learners learn words in context they also learn how to use them. On the other hand, when they memorize isolated words, they feel incompetent in using them to create meaning. Elaborating the importance of context in clarifying use, participants E explains:

Suppose the student faces the word "take" for the first time. If he memorizes the meaning of the word, he finds it hard to use it. On the other hand if he learns the phrases "take a shower", "take a taxi", "take a nap", "take a nap", simultaneously he learns how to use it to express his intentions. Similarly, if the learner learns the word "perpendicular" out of context, he or she will find it difficult to use it. On the other hand, if he learns the phrase, 
"perpendicular to the surface”, he can easily use it.

Participants further believe that it is the context that clarifies what the new word means. SDLLs who learn words in isolation wrongly suppose that each word has one meaning. Since words have multiple meanings, it is the context that clarifies what meaning is intended. Explaining how context specifies the meaning of words, participant F states:

Take the familiar word "do". When SDLLs see this word they think they know it. However, when they face phrases like "that will do it", and "do one's hair", they realize that they don't know it. As these phrases clearly show, what a word means depends on the context. As another example, the phrase "the bank of a river" shows what the word "bank" means. Not only does context specify the meaning of words, it also clearly shows how the word is used to create meaning.

\subsubsection{Watching Movies Actively}

SDLLs take a lot of time watching target language movies to improve their proficiency. Participants rejected these learners passive approach and, as an effective remedy, they proposed a two-phase process for actively watching movies: (1) removing subtitles to improve listening; and (2) adding subtitles to become cognizant with language forms.

\subsubsection{Removing Subtitles}

SDLLs watch target language movies with subtitles to improve their listening. Participants had a deem view of this strategy because what these learners actually do while watching movies is nothing but hastily reading the subtitles. This leaves no room for listening. Explaining the negative effect of subtitles, participant $\mathrm{G}$ points out:

SDLLswaste their time watching movies with English subtitles. They believe that watching movies with subtitles improves their listening skill. I personally believe that reading subtitles while watching a movie has a negative effect on listening because reading the subtitles shifts your attention away from listening towards reading. Further, I have a deem view of subtitles because they do not even improve one's reading since SDLLs are forced to read hastily.

Moreover, to be effective for language development, participants believed SDLLs should leave their couch, sit at the table, make notes to get the gist of interactions and later use their notes to improve their speaking. Participants believed that watching movies is effective if learners use the information they get from the movie to talk. To make effective use of movies, participant $\mathrm{H}$ recommends the following procedure:

To improve your proficiency through watching movies, I suggest that learners turn off the subtitles, listen selectively and jot down the plot and important themes. They can then use their notes to talk about the movie. More specifically, I believe in integrating listening and speaking activities. If watching the movie gives you some ideas to talk and improve your speaking, it will improve your language proficiency; otherwise, it is a waste of time.

\subsubsection{Adding Subtitles}

While removing subtitles help learners focus on meaning through a selective top-down approach towards listening, adding subtitles deepens the learners' overall understanding by making them cognizant with the way language forms are used in authentic interaction. Explaining the complementary nature of subtitles, participant $\mathrm{F}$ states:

Initially, participants should get an overall view of the movie without subtitles. This significantly improves their listening proficiency since they get used to getting the flow of information without being distracted by details of language forms. Adding subtitles and watching the movie again should aim at developing learners' mastery over language forms such as collocations, formulaic expressions and the like.

In addition to familiarizing learners with language form and the way they are used in daily interaction, adding subtitles help the learners correct any misconceptions formed when they watched the movie without subtitles. Explaining the complementary nature of subtitles and their role in improving listening, Participant D states:

Watching movies is an effective way of showing how language is used by native speakers, especially in EFL contexts where English has no social function; nonetheless, due to the rapid and fluent nature of conversational exchanges between native speakers, it is very difficult for language learners to understand and follow what is said. Adding subtitles is a good remedy for parts which are incomprehensible because of rapid use or noise.

\section{Discussion and Conclusion}

As the findings clearly show, SDLLs follow limited and limiting strategies. This is deeply rooted in the 
transmission model of language education which defines: (1) language teachers' role as transmitting a pre-specified body of knowledge to the learners; (2) learners' role as the passive recipient of information transmitted by the teacher. This situation is deteriorated since final exams have a gatekeeping function. That is, they assure officials at the central agencies that teachers present nothing but the specified content. Moreover, since textbooks are loaded with information, teachers see their main concern as covering the textbook. Under such conditions teachers find no time for strategy training. This has resulted in what we termed strategy deficiency syndrome. That is, learners struggle to learn the skills and components of the target language through self-constructed limiting strategies such as memorizing long lists of bilingual words to remedy their deficiency in listening, speaking, reading and writing. As another limiting strategy, they find dictionary use as the only technique of decoding the meaning of the texts.

What makes this study unique is its diagnostic and therapeutic view of strategy deficiency syndrome among EFL learners. It is diagnostic since participants' observation of SDLLs' struggle to develop their language proficiency and the interactive nature of this data-driven study unearthed learners' limiting strategies. It is therapeutic in nature, since it went beyond diagnosing inefficient strategies to teachers' proposed alternative strategies, which not only remedy the diagnosed problem but also create conditions that are conducive to learners' language growth and development. The findings, i.e., learners' limiting strategies and teachers' proposed alternatives, have clear implications for:

- Policy makers since their becoming cognizient with strategy deficiency syndrome may pave the way for a shift away from teaching towards strategy training;

- Curriculum developers since learners' limiting and limited strategies make it imperative for them to take strategy training as an unalienable part of materials development;

- Language teachers since learners' strategy deficiency together with its debilitating effect on their language development makes it imperative for them to make way for strategy training within the mainstream transmission model of education.

\section{References}

Abbott, M. L. (2006). ESL reading strategies: Differences in Arabic and Mandarin speaker test performance. Language learning, 56(4), 633-670. https://doi.org/10.1111/j.1467-9922.2006.00391.x

Broun, T. L., \& Oelwein, P. (2007). Literacy skill development for students with special learning needs. Port Chester, New York: Dude Publishing.

Catalan, R. M. J. (2003). Sex differences in L2 vocabulary learning strategies. International Journal of Applied Linguistics, 13(1), 54-77. https://doi.org/10.1111/1473-4192.00037

Cohen, D. A. (2002). Assessing and enhancing language learners' strategies. Hebrew Higher Education, 10, 1-11.

Day, R. R, \& Bamford, J. (1998). Extensive reading in second language classroom.Cambridge: Cambridge university press.

Diaz, S., \& Laguado, J. C. (2013). Improving reading skills through skimming and scanning techniques at a public school: Action research. Opening Writing Doors Journal, 10(1), 133-150.

Dornyei, Z. (1995). On the teachability of communication strategies. TESOL Quarterly, 29(1), 55-85. https://doi.org/10.2307/3587805

Ehrman, M., \& Oxford, R. (1989). Effects of sex differences, career choice, and psychological type on adult language learning strategies. The Modern Language Journal, 73(1), 1-13. https://doi.org/10.1111/j.1540-4781.1989.tb05302.x

Ehrman, M., \& Oxford, R. (1990). Adult language learning styles and strategies in an intensive training setting. The modern language journal, 74(3), 311-327. https://doi.org/10.1111/j.1540-4781.1990.tb01069.x

Hartmann, R. R. K. (2003). Lexicography: Dictionaries, compilers, critics and users. London, New York: Routledge Publication.

Nakatani, Y. (2005). The effects of awareness - raising training on oral communication strategy use. The Modern Language Journal, 89(1), 76-91. https://doi.org/10.1111/j.0026-7902.2005.00266.x

Oxford, R. L., \& Cohen, A. D. (1992). Language learning strategies: Crucial issues of concept and classification. Applied Language Learning, 3, 1-35.

Oxford, R. L. (1990). Languagelearning strategies: What every teacher should know. Boston: Heinle \& Heinle. 
Rizvi, A. (2005). Effective technical communication. New Delhi: Hill publishing company.

Rubin, J. (1975). What the "good language learner" can teach us. TESOL Quarterly, 9(1), 41-51. https://doi.org/10.2307/3586011

Rusinsky, T., \& Hymes, R. (2008). Making and writing words: Word families 40-sequenced word-building lessons. U.S.A: Corinne Burton.

Schmitt, N., \& Carter, R. (2000). Lexical Phrases in language learning. The language teacher, 24(8), 6-10.

Schmitt, N. (2004). Formulaic sequence: Acquisition, processing and use. Philadelphia: John Benjamin Publishing. https://doi.org/10.1075/11lt.9

Stern, H. H. (1975). What can we learn from the good language learner? Canadian Modern Language Review, 34, 304-318.

Ulmi, L. N. H., Sundari, S., \& Sukmaantara, I. P. (2015). The Effect of using skimming and scanning techniques on the Eighth grade Students' reading comprehension achievement of recount rexts at SMPN 1 Silo Jember.ARTIKEL ILMIAH MAHASISWA, I(1), 1-4.

Vandergrift, L. (2002). 'It was nice to see that our predictions were right': Developing metacognition in L2 listening comprehension. Canadian Modern Language Review, 58 (4), 555-575. https://doi.org/10.3138/cmlr.58.4.555

Wenden, A. \& Rubin, J. (1987). Learner strategies in language learning. Englewood Cliffs, NJ: Prentice Hall. https://doi.org/10.1111/j.1467-1770.1987.tb00585.x

Wood, D. (2002). Formulaic language in acquisition and production: Implications for teaching. TESL Canada Journal, 20(1), 1-15. https://doi.org/10.18806/tesl.v20i1.935

\section{Copyrights}

Copyright for this article is retained by the author(s), with first publication rights granted to the journal.

This is an open-access article distributed under the terms and conditions of the Creative Commons Attribution license (http://creativecommons.org/licenses/by/4.0/). 